REVIEW ARTICLE/ DERLEME YAZISI

\title{
Saklı Ada: Insula
}

\author{
Sevda LAFCI FAHRİOĞLU ${ }^{1}$, Sezgin İLGİ ${ }^{2}$
}

\begin{abstract}
Özet: Bu derleme yazısında insula'nın gros ve mikroskobik anatomisi, fizyolojik bağlantıları ve fonksiyonları ile çeşitli nörolojik ve psikiyatrik hastalıklardaki rolü hakkında bilgi verilmesi amaçlanmıştır. Beynin eksternal yüzünden bakıldığında görülemeyen, ancak sulcus lateralisaralandığında görünür hale gelebilen, korikal bir saha olan insula, son 25-30 yılda fonksiyonlarınınanlaşılmaya başlanması ve bazı nörolojik ve psikiyatrik hastalıkların mekanizmasındaki rolünün tartışılabilir hale gelmesiyle nöro-görüntüleme çalışmalarının da ilgi odağı olmuştur. Insula'nın olfaktor saha, corpus amygdaloideum, entorhinal saha, gyrus cinguli ve hippocampus ile olan bağlantıları limbik sistem ile birlikte önemli fonksiyonları olduğunun önemli kanıtlarındandır. Bu gereksinim 1şığında,insula hakkında literatürde yer alan bilgiler bir araya getirilmiştir. Limbik integrasyon ile visseral ve otonomik fonksiyonlardaki önemi sayesinde insula, demanstan şizofreniye kadar geniş bir yelpazede yer alan nöropsikiyatrik hastalıkların patomekanizmasında halen açıklığa kavuşturulmayı bekleyen birçok gizemi barındırmaktadır.
\end{abstract}

Anahtar Kelimeler: Insula; insular kortex; von Economo nöronları; bilişsel fonksiyon; limbik sistem.

\section{The Hidden Island: Insula}

\begin{abstract}
The insula cannot be seen from outside the brain. However, when you eliminate the lateral sulcus, you can observe the insula as a cortical region. In the last 25-30 years, as the scientific community is beginning to understand the function of the insula with respect to some neurological and psychiatric diseases, the neuroimaging studies of this region is becoming more popular. Insula's connections to the olfactory field, corpus amygdaloideum, entorhinal field, gyrus cinguli and hippocampus together with the limbic system are proof that the insula has very important functions. The insula is still the focus of crucial mysteries that are waiting to be shed light on in a wide array of neurological diseases ranging from dementia to schizophrenia, as a result of the importance of the insula's connection to the limbic system and the visceral and autonomic functions. In this review, we aim to offer the most up-to-date information on the gross and microscopic anatomy of the insula, its physiological and functional connections and its role in various neurological and psychiatric diseases.
\end{abstract}

Keywords: insula; insular cortex; von Economo neurons; cognitive functions; limbic system.

${ }^{1}$ Doç. Dr. Sevda Lafcı Fahrioğlu, Yakın Doğu Üniversitesi Tıp Fakültesi Anatomi AD.

${ }^{2}$ Prof. Dr. Sezgin İlgi, Yakın Doğu Üniversitesi Tıp Fakültesi Anatomi AD.

Address of correspondence / Yazışma adresi/: Doç. Dr. Sevda Lafcı Fahrioğlu, Yakın Doğu Üniversitesi, Tıp Fakültesi, Lefkoşa-Kıbrıs. Email: sevdalafci@gmail.com

Date of Received/ Geliş Tarihi: 25.04.2019, Date of Acceptance / Kabul Tarihi: 30.04.2019

Citing / Referans Gösterimi: Fahrioğlu Lafcı, S., İlgi, S., (2019). Saklı Ada: Insula. Kıbrıs Türk Psikiyatri ve Psikoloji Dergisi, 1 (1): 57-63 doi:10.35365/ctjpp.19.1.07 


\section{Insula Anatomisi}

Beynin major sulcuslarından biri olan sulcus lateralis (Sylvian fissure) aralandığında ortaya çıkan insula, ilk olarak 1796'da Alman nörolog Johann Reil tarafindan tarif edilmiştir (Nieuwenhuys, 2012; Standring, 2000). Bu sebeple Reil adası (Island of Reil) olarak da adlandırılan insula beşinci beyin lobu (lobus insularis) olarak bilinir (Şekil 1).

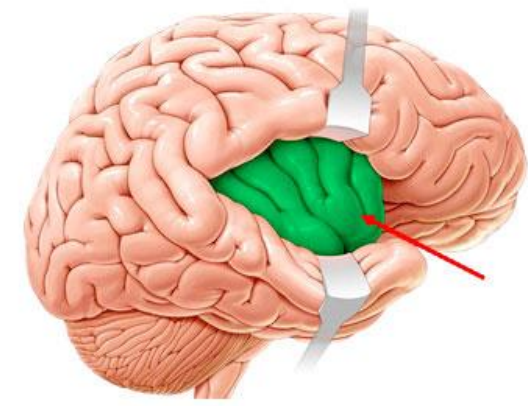

Şekil 1. Sulcus lateralis ekartörle aralandığında görünür hale gelen insula

Latince'de "ada" anlamina gelen insula, sulcus centralis insulae ile ön ve arka insula olmak üzere iki parçaya ayrılır. Otuz iki hemisfer diseksiyonu ile gerçekleştirilen bir tez çalışmasında, insula'nın \%16 oranında ön, orta ve arka olmak üzere üç parçadan oluştuğu veüç parçadanoluşan insula'nın \%60'ının sol, \% 40’’nın sağ hemisferde bulunduğu tespit edilmiştir. Ayrıca bu üçüncü parçanın 2 veya 3 gyrus'tan oluşabileceği bildirilmiştir (Senan, 2005). Ön parça (lobus anterior insula veya anterior insula) daha büyük, arka parça (lobus posterior insula veya posterior insula) ise daha küçüktür (Şekil 2).

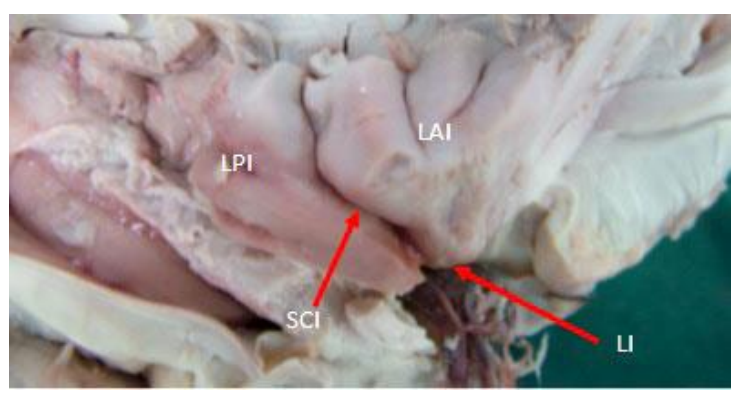

Şekil 2. Intrakraniyal patolojisi bulunmayan, 62 yaşındaki bir erkek kadavraya ait beyin diseksiyon materyali, sağ hemisferde yer alan insula görüntüsü. LPI: Lobus posterior insula, LAI: Lobus anterior insula, SCI: Sulcus centralis insula, LI: Limen Insula

$\mathrm{Bu}$ bölgelerde yer alan gyrus'lar sırasıyla, gyri breves insulae ve gyrus longus insulae olarak adlandırılır. Anterior parça (gyri breves insulae) üç veya dört kısa gyrus'dan, posterior parça (gyrus longus insulae) ise arka-üst uca doğru çatallanan bir uzun gyrus'tan olusur (Standring, 2000; Tanriover, ve ark., 2004; Stephani, ve ark. 2011). Frontal, temporal ve parietal lob'un insula'yı çevreleyen kısmına operculum adı verilir (Crossmann ve Neary, 2000). Diğer bir ifade ile insula, sulcus centralis etrafindaki frontal, parietal ve temporal loblara ait operculum parçaları çıkarılınca ortaya çıkan, dört veya altı gyrus'tan oluşan, piramidal şekilli korteks parçasıdır (Augustine, 1996; Uddin, 2017). Piramidin tepesi aşağı-öne doğru uzanır. Tepeden hemisferlerin bazal yüzüne doğru uzanan kısmına limen insulae adı verilir. Etrafi sulcus circularis insulae ile çevrelenmiştir (Standring, 2000) (Şekil 3).

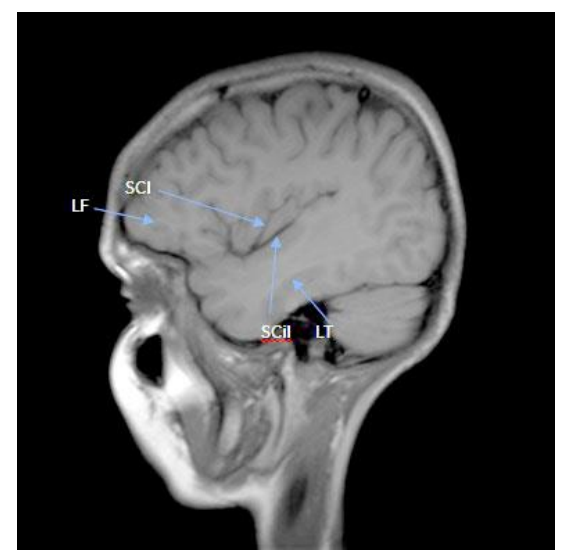

Şekil 3. Intrakraniyal patolojisi bulunmayan bir vakaya ait sagital MRG kesiti. LF: Lobus frontalis, SCI: Sulcus centralis insula, SCiI: Sulcus circularis insula, LT: Lobus temporalis

\section{Insula'nın Embriyolojisi}

Intrauterin dönemin ikinci ayında hemispherium cerebri'nin anterior, dorsal ve inferior yönlerde büyümeye devam etmesi sonucu, lobus frontalis, lobus temporalis ve lobus occipitalis oluşur. Üçüncü ayın sonunda, polus temporalis'in ön-üst ve hemisferlerin dış yüzünde, üçgen şeklinde çukur bir alan görülür. Lobus frontalis ve lobus temporalis arasındaki sıkı etkileşimden kaynaklanan bu alan, insula olarak adlandırılan bölgeyi meydana getirir (Kalani, 2009). Bu etkileşime, striatum'un lateral kısmı yassılaşarak katkıda bulunur. Lobus temporalis ve lobus frontalis orbita boşluğuna doğru uzamaya devam eder (Namkung, Kim ve Sawa, 2017; Standring, 2000). Bu büyüme sonunda, kortikal alanlarda katlanmalar görülmeye başlar. $\mathrm{Bu}$ katlanmalar, hemisferlerin dış yüzeyleri başlangıçta düz olduğu halde, gyrus ve sulcus'ların gelişmesi sayesinde, cranium boyutu çok fazla değişmeden korteks yüzeyinin genişlemesine (doğumda 700 $\mathrm{mm}^{2}$, iki yaşında $1700 \mathrm{~mm}^{2}$ ) firsat tanır. Insula, yakınındaki kortikal alanlardan daha yavaş büyüdüğü için, onlar tarafından çevrelenir. Insula'nın üzerini 
örten komşu kortikal sahalara operculum adı verilir (Standring, 2000, Uddin, 2017). Doğum sirasında insula'nın hemen tüm yüzeyi örtülmüş durumdadır. Fötal hayatın sonlarında, hemispherium cerebri'nin yüzeyinde pek çok gyrus görünür hale gelmiş olsa da bu gelişme doğumdan sonraki döneme kadar tamamlanamaz (Standring, 2000).

\section{Insula Histolojisi ve Fonksiyonları}

Insula, mesocortex olarak bilinen paralimbik bir yapıdır. Anatomik ve fonksiyonel olarak allocortex ve neocortex'in karıştığı bir alan olan insula, Brodmann'ın tarif ettiği fonksiyonel beyin alanlarından 13-16 nolu sahaları içerir. Lokalizasyonunun derinliği ve sulcus lateralis'in yoğun vaskülarizasyonundan dolayı, insula konusundaki histolojik bilgilere daha çok hayvanlarda yapılan çalısmalarla ulaşılmıştır. İnsan insula's1 Rhesus maymunlarının insula'sına benzer verostroventral agranüler saha, transizyonel disgranüler saha, caudodorsal granüler saha olmak üzere üç hücre tabakasından meydana gelmiştir (Mesulam ve Mufson, 1985; Mufson ve Mesulam, 1982, Mufson ve Mesulam, 1984). Maymun ve insanlarda anterior insula'da Von Economo Nöronlarını (VEN) da bulunduğu anlaşılmıştır (Allman, 2011). Rostroventral agranüler saha olfaktor ve otonomik fonksiyonlarla, transizyonel disgranüler saha tat fonksiyonuyla ve caudodorsal granüler saha somatik duyu, işitme ve görme fonksiyonlarıyla ilgilidir (Preuss ve Goldman., 1989). Agranüler korteks yapısında olan anterior insular korteks'in, gyrus cingularis'in anterior k1sm1, prefrontal korteks'in dorsolaterali, sitriatum ve amygdala ile resiprokal bağlantıları bulunur (Allman ve ark., 2011; Augustine, 1996; Bossaerts, 2010). Anterior insula bu bağlantıları ile, emosyonel, kognitif ve motivasyonel fonksiyonlardaki otonomik ve visseral entegrasyondan sorumludur (Frank, Kullmann ve Veit, 2013). Posterior insular korteks ise granüler korteks yapısındadır, thalamus aracılığı ile beyin sakı ve medulla spinalis'ten ayrica parietal, occipital ve temporal korteks'ten de impuls alır (Kim ve ark., 2017; Nagao ve ark., 2017; Nambkung ve ark. 2017; Nieuwenhuys, 2012). Beynin diğer bölümleri ile insula'nın baglantısı histolojikyapısıyla ilgilidir (Mutschler, 2009). Primatlarda lobus insularis'in, cortex cerebri,nuclei basales ve limbik yapılarla bir çok bağlantısı olduğu bilinmektedir (Mufson, ve Mesulam, 1982; Mufson, ve Mesulam 1984; Preuss ve Goldman, 1989). Medial temporal lob epilepsisi (MTLE) tanısı alan ancak medikal tedaviye cevap vermeyen ve epilepsi cerrahisine yönlendirilen 5 hastaya intraoperatif uygulanan elektrotlar vasitasıyla uyarı verilerek elde edilen bilgiler ve insular lezyonları olan epilepsi hastalarının klinik bulguları da insan insula'sına 1şıktutmaktadır (Bouilleret, 2002; Ryvlin, ve Picard, 2017; Ostrowsky ve ark., 2000). Mesulam ve Mesulam $(1982,1984)$ ile Frederick ve ark.'nın (2001) çalısmalarında insula'nın, dil, visseromotor, sensorimotor, suplementer motor vekognitif fonksiyonlarda önemli bir rol aldığ1 vurgulanmıştır. Ayrıca, insula'nın olfaktor saha, corpus amygdaloideum, entorhinal saha, gyrus cinguli ve hippocampus ile bağlantılar, limbik sistem ile olan bağlantısını açıklayıcı niteliktedir (Mutschler, 2009; Mufson, ve Mesulam, 1982; Mufson, ve Mesulam 1984). Yapılan elektrofizyolojik çalışmalar ile insan lobus insularis'inde de butopografik organizasyon doğrulanmıstır. Bouilleret ve ark.'nın yaptığı çalışmada (2002:51) positron emisyon tomografi (PET) ile epileptik nöbetlerin ortaya çıkıs semptomlarının nöroanatomik korelasyonu ortaya konmuştur. Insula'nın area olfactoria, corpus amygdaloideum, entorhinal cortex, gyrus cinguli ve hippocampus gibi temporo-limbik yapilarile olan bağlantıları nedeniyle "limbik epilepsi', etyolojisinden sorumlu olabileceği düşünülmektedir (Ostrowsky, 2000). Ayrica temporallob epilepsisi (TLE) olan hastaların nöbetsemptomlarının, insularkorteks situmulasyonu sonucu oluşan semptomlar ile benzerlik gösterdigi literatürde bildirilmiştir. $\mathrm{Bu}$ benzerlik, lobus insularis ile temporo-limbik yapılar arasında varolan yoğun bağlantılar sayesinde açıklanabilir (Venniro, 2017 Frederick, 2001).

\section{Insula'nın Nörolojik ve Psikiyatrik Hastalıklardaki Yeri}

Insula visseral, otonomik ve affektif fonksiyonlarda rol alır (Augustine, 1996; Crespo-Facorro, 2000). Insula'nın, kardiyak regulasyonda önemli bir görevi vardır. Özellikle sol insulakardiyak parasempatik etkiden sorumludur (Bossaerts, 2010; Oppenheimer, Kedem, ve Martin, 1996). Insula'nın fonksiyonel özellikleri de yine son 20 yılda yapılan çalışmalar sayesinde anlaşılmaya başlanmıştır (Abdolahi, 2015; Allman, 2011; Bossaerts, 2010). Çeşitli deneysel ve klinik çalısmada insula'nın hafıza, duygudurum, otonomik kontrol, koku ve tat duyularında rol oynadığı gösterilse de bunların dışında birçok görevinin hala anlaşılamadığı düşünülmektedir (Gogolla, 2017). Memelilerde tat korteksi'ne ait bir bölüm olduğu için "iğrenme" hissinin somatik ve visseral ifadesinden sorumludur (Suzuki, 2010; Suzuki, 2012). Insula'nın gyrus cinguli, nuclei basales, corpus amygdaloideum ve diğer limbik yapılarla ve thalamus'un dorsal nucleus'u ile bağlantılarının gösterilmiş olması, emosyonel fonksiyonu hakkında oldukça önemli bilgileri ortaya 
çıkartmıştır (Uddinve ark., 2017; Venniro, ve ark., 2017). Ayrica temporal ve parietal lob ile olan bağlantıları ile visseral motor saha, visseral duyu sahas1, suplementermotor saha, vestibuler saha ve konuşma ile ilgili saha olarak da görev yaptığı bilinmektedir (Stephani, ve ark., 2011). Özellikle sol insula'ua ait gyrus precentralis'in, konuşma koordinasyonundan sorumlu olduğu kabul edilmektedir (Nagao, ve ark., 1999).

Dış dünyadaki nesnelere karşı oluşan duygusal deneyimleme, bu nesnenin kognitif algılanması ve ardından bu algıya karşı oluşturulan bedensel tepki olarak ortaya çıkmaktadır (Mutschler, ve ark., 2009). Anterior insula fiziksel uyaran yoğunluğunu algilama gibi kognitif subjektif hisler ile aktive olmaktadır. Insula bu uyaranların bedende oluşturduğu tüm intraseptif uyarıları alarak, prefrontal korteks ile resiprokal bağlantıları vasitasıyla bu uyaranlar hakkında bilinç seviyesinde bir algı oluşmasını sağlar (Bossaerts, 2010; Namkung, Kim ve Sawa, 2017). Bu fonksiyonu insula'nın bağımlılıkta, özellikle sigara bağımlılığında yapılmış çeşitli çalışmalardan anlaşıldığ1 üzere, önemli bir rolü olduğunu göstermektedir (Abdolahi, ve ark., 2015; Suñer-Soler, ve ark., 2012). Abdolahi ve ark.'nın (2015) akut iskemik inme hastalarında gerçekleştirdikleri çalışmada, inme sonrası insular korteks hasarı tespit edilen hastalarda, inmeden sonraki 3 aylık dönemde sigara bırakma oranının, non-insular hasar tespit edilen hasta grubundaki sigara bırakma oranına göre istatistiksel olarak anlamlı şekilde yüksek olduğu gösterilmiştir. $\mathrm{Bu}$ bulgular, insular korteks'in sigara içme davranışı ve nikotin yoksunluk semptomlarının devamındaki potansiyel rolünü de desteklemektedir. Son yillarda fonksiyonel görüntüleme yöntemleri ile yapılan çalışmalar sayesinde, insular korteks'in bir çok nörolojik ve psikiyatrik hastalıkta etkilenen bir beyin bölgesi olduğu da anlaşılmaktadır (Nodine cell dergisi). Büyük bipolar nöronlar olanVEN'ları insanlarda, kognitif ve emosyonel fonksiyonlarda önemli görevleri olan anterior singulat korteks ve anterior insular kortex yapısında yer aldığ bilinmektedir. Intrauterin dönemin 36. haftasında görülmeye başlayan bu nöronlar, doğumdan sonraki ilk 8 ayda artar. Otonomik sistemin asimetrisine uygun olacak şekilde sağ insula'da daha fazla sayıda VEN bulunmaktadır. Bu tip nöronlar, temel bilgileri fronto-insular korteks ve anterior limbik bölgeden beynin diğer bölgelerine hızla iletebilirken, piramidal tip hücreler daha detaylı bilgilerin iletiminden sorumludur (Allman, ve ark., 2011; Krause, Theissve Brüne, 2017).

Fonksiyonu tüm detayları ile anlaşılamamış olan VEN'nın, şizofreni patomekanizmasında rol aldığ1 bilinmektedir. Şizofreni ve düşük dereceli bipolar olguların post-mortem doku incelemelerinde VEN'daki lizozomal agregasyon miktarının, normal bireylerdekine kıyasla daha fazla olduğu tespit edilmiştir (Krause, ve ark., 2017). Ayrica frontotemporal demans'in erken evrelerindeki empati, sosyal farkındalık, self-kontrol kaybının VEN'ın destrüksiyona sekonder olarak geliştiği radyolojik görüntüleme teknikleri ile yapılan çalışmalardan anlaşılmaktadır (Allman, ve ark., 2011). Limbik integrasyonun temel bileşeni olan insula'nın, lokasyonu ve etrafını çevreleyen korteks ve limbik sistem bağlantıları sebebiyle nörogelişimsel bazı hastalıkların oluşumunda yer aldığı düşünülmektedir (Moon, Moon ve Han, 2015; Parellada ve ark., 2017). Insula, uygun sosyal etkileşimler için gerekli olan öz farkındalık fonksiyonu ile sosyal bilişselliğe ve buna dayanan sosyal davranışlara etki eden bir korteks bölümüdür. Otizm Spektrum Bozuklukları (ASD) ve psikozda sosyal bilişsellikteki eksiklikler, insula'nın ön ve arka bölgelerindeki azalmış hacim ve kalınlık sonucu ortaya çıkan semptomatoloji ile bağlantılı olabilecek yapisal patolojinin kanitı olabilir (Parellada ve ark., 2017). Şizofreni hastalarının beyin magnetik rezonans görüntülerinin (MRG) incelemesinde özellikle frontal, temporal ve parietal heteromodal assosiasyon korteksinde kortikal incelme olduğu anlaşılmıştır (Roiz-Santiáñe ve ark., 2010). Post- mortem histolojik çalışmalarda şizofreni hastalarınıninsular korteksinde bulunan nöronların somalarında azalma saptanmıştır. Ayrıca orbitofrontal korteks, hipokampus, amygdala ve insula arasında bağlantıyı sağlayan fasciculus uncinatus'ta da anormallikler saptanmıştır (Penningtonve ark., 2008). Şizofreni hastalarının nöroradyolojik incelemelerinde özellikle anterior singulat gyrus ve insula'da gri cevher miktarında azalma yani kortikal incelme ile birlikte, özellikle sağ insular volumde azalma tespit edilmiştir. Bazı araştırmalarda halüsinasyonların içsel konuşma ve hastanın içsel olarak ürettiği eylemlerle ilgili olduğu belirtilmektedir. Anterior insula'nın dorsal k1smı işitsel ve dilin motor fonksiyonunun entegrasyonundan sorumlu iken, ventral k1smı emosyonel duruma bağlı olarak gelişen fizyolojik değişikliklerden sorumludur (Mutschler ve ark., 2009). Şizofreni hastalarında halüsinasyonlar sırasında artmış insular aktivite tespit edilmiştir (Psikozis). Alzheimer tipi demansta insula'nın, hastada gözlenen nöropsikiyatrik semptomlar, kardiyovasküler ve otonomik fonksiyonların değişimi ve mortalite ile ilişkili olduğunu belirten çalışmalar vardır. Alzheimer'da beyin volumünde düşüş ve korteks'te bir incelme mevcuttur (Foundas ve ark., 1997). Insula volumundeki değişim Alzheimer tipi demansın derecesi ile ilgili değilken, diğer bölgelerdeki kortikal atrofinin derecesi demansın 
derecesi ile ilgilidir. Alzheimer vakalarındaki insular atrofi mekanizmasının, genel korteks atrofisini oluşturan mekanizmadan farklı olduğu düşünülmektedir (Moon ve ark., 2015). Literatürde insula ve epilepsi ile ilgili son dönem çalışmaları dikkat çekmektedir (Bouilleret ve ark., 2000; CrespoFacorro ve ark., 2000; Guenot ve Isnard, 2008; Isnard, ve Mauguière, 2005; Obaid, Zerouali ve Nguyen, 2018; Obaid, ve ark., 2017). Talairach stereonsefalografi kullanılarak yapılan çalışmalarda, insular deşarj ile oluşan epileptik nöbet semptomlarının, temporal lob epilepsi (TLE) nöbetlerindeki semptomlara benzerliği dikkat çekmiştir. Insular deşarj ile oluşan nöbetler oroalimenter, toraks ve abdomende sıkışma hissi ve solunumsal semptomlar şeklindedir (Sun, Wang, ve Cui., 2015). Temporal lob kaynaklı nöbetler, elektriksel yayılım ile insula'yı da içerecek şekilde yayılabilirken, vakaların çok az bir kısmında (\%10) sadece insula'dan kaynaklı nöbetler rapor edilmiştir. (Isnard ve Mauguière, 2005). Yeme bozukluklarındaki visseral duyu sapmalarının varlığ özellikle anoreksia nervosa'nı (AN) patofizyolojisinde insula'nın önemine yönelik araştırmalar için yeni bir yol çizmektedir (Kim ve ark., 2017). Yeme bozukluklarının patofizyolojisinde de bedenin iç duyumlarından (intraseptörlerden gelen bilgiler) haberdar olmayı sağlayan insula'da fonksiyonel değişiklikler saptanmıştır (Schienle ve ark. 2005; Schienle ve ark., 2017). Insular korteks dışsal uyarılara karşı gelişen içsel yanıtları da entegre ettiği için yeme üzerinde asıl kontrolör olan hipotalamus'tan farklı bir yolla, iştahın nöronal kontrolünden ve enerji dengesinin düzenlenmesinden sorumludur (Frank ve ark., 2013). Literatürde fonksiyonel MRI (fMRI), Pozitron emisyon tomografisi (PET) ve Single Photon Emission Computerized Tomography (SPECT) ile yapılmış çeşitli çalışmalarda yeme bozukluğu olmayan, acıkmış bireylere gösterilen yemek resimleri ile tüm beyinde, özellikle superior temporal, sağ insular, orbitofrontal ve parietal korteks'te,ventral sitriatum ve amygdala'da metabolizma artış1 görüldüğü bildirilmiştir (Karhunen ve ark. 1997; Porobska, ve ark. 2006; Wang ve ark. 2008). T1kanırcasına yeme bozukluğu (Binge-eating Disorder) olanlara ve kontrol grubuna yüksek kalorili yiyecek resmi gösterilerek gerçekleştirilen fMRI çalışmasında, hasta grubunda, yeme bozukluğu olmayan kontrol grubuna göre, daha fazla artmış medial orbital korteks aktivitesi gözlenmişken, blumik hastalarda artmış anterior cingulat korteks ve insula aktivitesi gözlenmiştir (Schienle ve ark., 2009). Yeme bozukluklarında, özellikle AN'da, görüntüleme teknikleri ile yapılan çalışmalarda ventriküler hacmin artışı ile birlikte beyin hacminde azalma saptanmıştır (Güney ve Kuruoğlu, 2006). Kognitif, tutumsal, algısal ve deneysel bileşenler ile meydana gelenbeden imgesi, anoreksik hastalarda bozulmaktadır. Visseral duyuları alıp, entegre eden ve anlamlandırılan insular kortex,otonomik, kognitif ve affektif süreçlerde bütünleştirici bir etkiye sahiptir. Gastrointestinal sıkıntılar, yeme güçlüğü gibi hastalık başlamadan önceki somatik semptomlar, posterior insula'da, bunları anlamlandırma ve yorumlamadaki farkl1liklar anterior insula'da morfolojik değişikliklere yol açabilir (Zucker ve ark., 2017). Bu durum, AN'li hastaların hem posterior hem de anterior insula'larında hipometabolizma ve kan akımında azalmaya sebep olabilir. Kortikal bağlantıları ile emosyonel, kognitif ve motivasyonel fonksiyonlarda otonomik ve visseral entegrasyondan sorumlu bir bölge olan anterior insula'daki fonksiyon değişiklikleri ve volum azalması anoreksik hastalarda karşılaşılabilen bir durumdur. AN'de vücut imgesinin bozulmanın seviyesi tedavi başarısını da etkileyen önemli parametrelerdendir (Zucker ve ark., 2017).

\section{Sonuç}

Anatomik lokasyonunun 18.yy'daki tarifinden bugüne kadar, kortikal bağlantıları ve fonksiyonları hakkında giderek daha çok bilgi sahibi olduğumuz insular korteks, özellikle nörolojik ve psikiyatrik hastalıkların patofizyolojisindeki yeri ve önemi hakkındaki gizemi hala korumakta olan bir beyin lobudur. Geniş vaka serilerinde yapılacak nöroradyolojik çalışmalar, insular korteks hakkında daha fazla bilgi sahibi olmamızı sağlayacaktır.

\section{Kaynaklar}

Abdolahi, A., Williams, G.C., Benesch, C.G., Wang, H.Z., Spitzer, E.M., Scott, B.E., ... van Wijngaarden, E. (2015). Smoking cessation behaviors three months following acute insular damage from stroke. Addict Behav. Dec; 51:24-30.

Afif, A., ve Mertens, P. (2010). Description of sulcal organization of the insular cortex. Surg Radiol Anat 32:491-498.

Allman, J. M., Tetreault, N. A., Hakeem, A. Y., Manaye, K. F., Semendeferi, K., Erwin, J. M., ... Hof, P. R. (2011). The von
Economo neurons in the frontoinsular and anterior cingulate cortex. Annals of the New York Academy of Sciences, 1225, 59-71.

Augustine, J.R., (1996). Circuitry and functional aspect of the insular lobe in primates including humans, Brain Research Reviews, 22:229-244.

Bossaerts, P. (2010). Risk and risk prediction error signals in anterior insula. Brain Struct Funct. Jun;214(5-6):645-53.

Bouilleret, V., Dupont, S., Spelle, L., Baulac, M., Samson, Y., Semah, F. (2002). Insular Cortex Involvement in Mesiotemporal 
Lobe Epilepsy: A Positron Emission Tomography Study, Ann. Neurol. 51:202-208,

Crespo-Facorro, B., Kim, J., Andreasen, NC., O'Leary, DS., Bockholt, HJ., Magnotta V. (2000). Insular cortex abnormalities in schizophrenia: a structural magnetic resonance imaging study of first-episode patients. Schizophr Res. Nov 30; 46(1):35-43.

Crossmann A.R., ve Neary, D. (2000). Neuroanatomy an Illustrated Colour Text, Second edition, 89-160, Churchill Livingstone.

Foundas, A.L., Leonard, CM., Mahoney, SM., Agee, OF., Heilman, KM. (1997). Atrophy of the hippocampus, parietal cortex, and insula in Alzheimer's disease: a volumetric magnetic resonance imaging study. Neuropsychiatry Neuropsychol Behav Neurol. Apr;10(2):81-9.

Frank, S., Kullmann, S., ve Veit R. (2013). Food related processes in the insular cortex. Front Hum Neurosci. Aug 23;7:499.

Frederick F. Lang, Olansen N., Franco Demonte, Gökaslan Z.L., Holland E.C., ve Sawaya, R., (2001). Surgical resection of intrinsic insular tumors: complication avoidance, J Neurosurg 95:638-650.

Gogolla, N. (2017). The insular cortex. Curr Biol. 2017 Jun 19;27(12): 580-R586.

Gogolla, N., Anne, E., Takesian, Feng, G., Fagiolini, M., ve Takao K. (2014). Hensch Sensory Integration in Mouse Insular Cortex Reflects GABA Circuit Maturation. Neuron. Aug 20;83(4):894905.

Guenot, M., Isnard, J. (2008). Epilepsy and insula Neurochirurgie. May;54(3):374-81.

Güney, E., ve Kuruoğlu, A. Ç. (2007). Yeme Bozukluklarında Beyin Görüntüleme Yöntemleri. Klinik Psikiyatri Dergisi, 10(2).

Isnard, J., Mauguière, F. (2005). The insula in partial epilepsy. Rev Neurol (Paris). Jan;161(1):17-26.

Kalani MY, Kalani MA, Gwinn R, Keogh B, Tse VC. (2009) Embryological development of the human insula and its implications for the spread and resection of insular gliomas. Neurosurg Focus. Aug;27(2):E2.

Kim, J., Zhang, X., Muralidhar, S., LeBlanc, SA., ve Tonegawa, S. (2017). Basolateral to Central Amygdala Neural Circuits for Appetitive Behaviors. Neuron. Mar 22;93(6):1464-1479.e5.

Krause, M., Theiss, C., ve Brüne M. (2017). Ultrastructural Alterations ofvon Economo Neurons in the Anterior Cingulate Cortex in Schizophrenia. Anat Rec (Hoboken). Nov;300(11):20172024.

Mesulam, M.M., ve Mufson, E.J. (1985). The insula of reil in man and monkey. Architectonics, connectivity, and function, in Peters A, Jones EG: Cerebral Cortex., vol 4, :179-226.

Moon, Y., Moon,, WJ., ve Han, SH. (2015). Pathomechanisms of atrophy in insular cortex in Alzheimer's disease. Am J Alzheimers Dis Other Demen. Aug;30(5):497-502.

Mufson, E.J., ve Mesulam, M.M. (1982). Insula of the old-world monkey. I. Architectonics in the insulo-orbito-temporal component of the paralimbic brain. Com Neurol. Nov.20;212(1):1-22.

Mufson, E.J., ve Mesulam, M.M. (1984). Thalamic connections of the insula in the rhesus monkey and comments on the paralimbic connectivity of the medial pulvinar nucleus. J Comp Neurol. Jul 20;227(1):109-20.

Mutschler, I., Wieckhorst, B., Kowalevski, S., Derix, J., Wentlandt, J., Schulze-Bonhage ve A., Ball, T. (2009). Functional organization of the human anterior insular cortex. Neurosci Lett.Jun 26;457(2):66-70.

Nagao, M., Takeda, K., Komori, T., Isozaki, E., ve Hirai, S. (1999). Apraxia of speech associated with an infarct in the precentral gyrus of the insula. Neuroradiology 41:356-357.

Namkung, H., Kim, S.H., ve Sawa, A. (2017). The Insula: An Underestimated Brain Area in Clinical Neuroscience, Psychiatry, and Neurology. Trends Neurosci. Apr;40(4):200-207.

Nieuwenhuys, R., (2012). The insular cortex: a review. Prog Brain Res.195:123-63.

Obaid S, Zerouali Y, Nguyen DK. (2017) Insular Epilepsy: Semiology and Noninvasive Investigations. J Clin Neurophysiol. Jul;34(4):315-323.

Obaid, S., Tucholka, A., Ghaziri, J., Jodoin, P.M., Morency, F., Descoteaux M, ... ve Nguyen D.K. (2018) Cortical thickness analysis in operculo-insular epilepsy. Neuroimage Clin. May 31;19:727-733.

Oppenheimer, S.M., Kedem, G., ve Martin, W.M., (1996). Leftinsular cortex lesions perturb cardiac autonomic tone in humans, Clin. Auton Res, 6(3)131-40.

Ostrowsky. K., Isnard, J., Ryvlin, P., Guénot, M., Fischer, C., Mauguière, F. (2000). Functional mapping of the insular cortex: clinical implication in temporal lobe epilepsy. EpilepsiaJun;41(6):681-6.

Parellada, M., Pina-Camacho, L., Moreno, C., Aleman, Y., Krebs, MO., Desco, M., ... Janssen J. (2017). Insular pathology in young people with high-functioning autism and first-episode psychosis. Psychol Med.Oct;47(14):2472-2482.

Pennington, K., Dicker. P., Hudson, L., Cotter, D.R. (2008) Evidence for reduced neuronal somal size within the insular cortex in schizophrenia, but not in affective disorders. Schizophr Res. Dec;106(2-3):164-71.

Porubska,K., Veit,R., Preissl,H., Fritsche,A.,and Birbaumer,N. (2006). Subjective feeling of appetite modulates brain activity:and MRI study. Neuroimage 32, 1273-1280.

Preuss, T.M. ve Goldmsn-Rakic, P.S., (1989). Connection of the ventral granuler frontal cortex of macaques with perisylvian premotor and somatosensory areas:anatomical evidence for somatic representation in primate frontal association cortex, $J$. Comp. Neurol 282, 293-316.

Roiz-Santiáñez, R., Pérez-Iglesias, R., Quintero, C., TordesillasGutiérrez, D., Mata, I., Ayesa, R., ... Crespo-Facorro, B. (2010). Insular cortex thinning in first episode schizophrenia patients. Psychiatry Res. Jun 30;182(3):216-22.

Ryvlin, P., Picard, F. (2017) Invasive Investigation of Insular Cortex Epilepsy. J Clin Neurophysiol. Jul;34(4):328-332.

Schienle, A., Schäfer, A., Hermann, A., ve Vait, D. (2009). Bingeeating disorder: reward sensitivity and brain activation to images of food. Biol Psychiatry. Apr 15;65(8):654-61.

Senan, S. (2005). Insula Anatomisinin Morfometrik Olarak ve Manyetik Rezonans Görüntüleme Yöntemi ile İncelenmesi (Yayımlanmamış doktora tezi) Hacettepe Üniversitesi/Sağlık Bilimleri Enstitüsü, Ankara.

Standring, S. (Ed.) (2000). Gray's Anatomy, The anatomical basis of clinical practise, (39. Bask1). Elsevier.

Stephani, C., Fernandez-Baca, G., Maciunas, R., Koubeissi, M., ve Lüders, HO. (2011). Functional neuroanatomy of the insular lobe. Brain Struct Funct. Jun;216(2):137-49. 
Sun, T., Wang, F., ve Cui J. (2015) Insular Cortex and Insular Epilepsy, Journal of Neurology and Neuroscience, Vol. 6 No. 2:9.

Suñer-Soler, R., Grau, A., Gras, M.E., Font-Mayolas, S., Silva, Y., Dávalos, A., ... Serena, J., (2012). Smoking cessation 1year poststroke and damage to the insular cortex. Stroke. Jan;43(1):131-6.

Suzuki A. (2010) Insula and disgust Rinsho Shinkeigaku. 2010 Nov;50(11):1000-2.

Suzuki A., (2012) Emotional functions of the insula, Brain Nerve. Oct;64(10):1103-12.

Tanriover, N., Rhoton, AL Jr., Kawashima, M., Ulm, A.J., ve Yasuda, A. (2004). Microsurgical anatomy of the insula and the sylvian fissure. J Neurosurg. May;100(5):891-922.
Uddin, L. Q., Nomi, J. S., Hébert-Seropian, B., Ghaziri, J., ve Boucher, O. (2017). Structure and Function of the Human Insula. Journal of clinical neurophysiology: official publication of the American Electroencephalographic Society, 34(4), 300-306.

Venniro, M., Caprioli, D., Zhang, M., Whitaker, L. R., Zhang, S., Warren, B. L., ... Shaham, Y. (2017). The Anterior Insular Cortex $\rightarrow$ Central Amygdala Glutamatergic Pathway Is Critical to Relapse after Contingency Management. Neuron,96(2), 414427.e8.

Wang, G.J., Tomasi, D., Backus, W., Wang, R., Telang, F., Geliebter, A., (2008). Gastric distention activates satiety circuitry in the human brain. Neuroimage 39, 1824-1831.

Zucker, N.L., Kragel, P.A., Wagner, H.R., Keeling, L., Mayer, E., Wang, J., ... LaBar, KS. (2017). The Clinical Significance of Posterior Insular Volume in Adolescent Anorexia Nervosa. Psychosom Med. 79(9): 1025-1035. 